\title{
Educar para prevenir: proteção e defesa civil nas escolas por um currículo escolar vivo
}

\author{
Lucilene de Freitas Baeta \\ Instituto Federal de Educação, Ciência \\ e Tecnologia de São Paulo, IFSP. \\ Iucilene_baeta@yahoo.com.br \\ Natália Leite de Morais \\ Instituto de Geociências, Univ. de São \\ Paulo, IGc/USP. \\ natalia.leitemorais@hotmail.com
}

\begin{abstract}
EDUCATING FOR PREVENTION: PROTECTION AND CIVIL DEFENSE IN SCHOOLS FOR A LIVE SCHOLAR CURRICULUM. This work presents a project of CAPR - "Coordenadoria de Ações Preventivas e Recuperativas" (Coordination of Preventive and Recuperative Actions), a subdivision of the Comdec - "Coordenadoria Municipal de Defesa Civil" (Municipal Coordination of Civil Defense), which proposes the integration of the communities located in risk areas with the Civil Defense, in order to create a culture of planning and implementing preventive actions with the school as reference. Taking as pilot the subprefecture of São Mateus, in São Paulo city, questionnaires were applied on the Board of Education that serves the region to carry out a survey of the perceptions of citizens regarding events in high-risk areas. Thus, the schooling, which would begin introducing concepts that exalt the formation of a conscious citizen, would be the first step to generate ownership of subjects that appear constantly in the daily lives of students residing in locations prone to natural events such as landslides, floods, etc. Contribute to the education creating practices of awareness in the community requires an effort to awaken the residents who live around the school to participate in collective actions seeking improvements to their neighborhood. Thus, the integration of activities of Civil Defence and local city schools will demonstrate the efficiency of public policies intended to serve society, but also encourage the formation of critical citizens who can look for better conditions in the city in which they live. Citation:Baeta L.F., Morais N.L.de. 2014. Educar para prevenir: Proteção e Defesa Civil nas escolas por um currículo escolar vivo. Terræ Didatica, 10(3):336-345. http://www.ige.unicamp.br/terraedidatica/.
\end{abstract}

KEYWORDS: Geology teaching, civil defense, natural disasters, didatic tool.

RESUMO Este trabalho apresenta um projeto da Coordenadoria de Ações Preventivas e Recuperativas, a CAPR, uma subdivisão da Coordenadoria Municipal de Defesa Civil, a Condec, que propõe a integração entre as comunidades situadas em áreas de risco e a Defesa Civil, com o intuito de criar uma cultura de planejamento e execução de ações preventivas tendo a escola como referência. Tomando como piloto a subprefeitura de São Mateus, município de São Paulo, foram aplicados questionários na Diretoria de Ensino que atende a região para se realizar levantamento da percepção dos munícipes em relação a eventos em áreas de risco. Assim, a formação escolar, que iniciaria a introdução de concepções que exaltam a formação de um cidadão consciente, seria o primeiro passo para gerar a apropriação de assuntos que aparecem constantemente no cotidiano de estudantes residentes em localidades propícias a eventos naturais como escorregamentos, enchentes, inundações, deslizamentos etc. Contribuir para a educação criando práticas de conscientização na comunidade requer um esforço de despertar os munícipes que habitam no entorno da escola a participar de ações coletivas em busca de melhorias para o seu bairro. Assim, a integração de atividades da Defesa Civil e escolas do município demonstrará a eficiência das políticas públicas que pretendem atender a sociedade, mas também incentivar a constituição de cidadãos críticos que saibam buscar por melhores condições na cidade em que vivem.

PALAVRAS-CHAVES: Ensino de Geologia, defesa civil, desastres naturais, recurso didático. 


\section{Introdução}

As periferias das grandes metrópoles brasileiras, como Rio de Janeiro, São Paulo e Salvador, por exemplo, são marcadas pelas moradias irregulares em locais propícios a acidentes geológicos e ambientais, e acredita-se que o uso e ocupação do solo ocorram de maneira imprópria por, principalmente, falta de melhores oportunidades, mas também por desconhecimento dos riscos por parte da população. Portanto, a inserção de trabalhos educacionais nessas regiões é de extrema importância para minimizar a suscetibilidade de acidentes.

Visando aprimorar a integração entre as escolas, os órgãos públicos, a Defesa Civil e as comunidades situadas em áreas de risco, a Coordenadoria de Ações Preventivas e Recuperativas propõe a execução do projeto "Educar para prevenir: Proteção e Defesa Civil nas escolas por um currículo escolar vivo" que insere seu papel preventivo e educativo no cotidiano escolar a fim de difundir, para com os docentes, os conhecimentos técnicos relacionados à temática dos riscos geológicos e ambientais. $\mathrm{O}$ projeto também procura incentivar a organização e participação nos Núcleos de Defesa Civil (Nudec), para que a população não fique inteiramente dependente das ações dos órgãos públicos e possa se organizar e prevenir de possíveis situações adversas.

Por meio de orientações técnicas a respeito do tema, é esperado que os docentes consigam correlacionar os assuntos previstos nas diretrizes curriculares com as temáticas de risco geológico, sendo possível, então, o desenvolvimento das atividades e metodologias propostas neste projeto. Também é esperado que, com o devido aprofundamento, a difusão dos conhecimentos técnicos adquiridos estimule os alunos a tornarem-se multiplicadores do conhecimento em seus bairros, permitindo que a população local adquira a percepção de risco geológico e da problemática socioambiental em que estão inseridos e utilize tais conhecimentos em prol da prevenção e gerenciamento dos riscos que atingem a região.

\section{Diagnóstico da Unidade}

Para aplicação do projeto, idealizou-se a realização de um projeto piloto nas escolas municipais da subprefeitura de São Mateus, Zona Leste da cidade de São Paulo. Tal escolha ocorreu com a finalidade de respeitar as escalas do espaço geográfico, que são, sequencialmente, bairro, cidade, estado, país e continente, e também devido à maior facilidade de comunicação com a Diretoria Regional de Ensino de São Mateus.

O distrito de São Mateus, juntamente com mais dois distritos vizinhos, São Rafael e Iguatemi, é gerenciado pela subprefeitura de São Mateus, que é uma dentre as 31 subprefeituras da cidade de São Paulo (Fig. 01) e possui área total de 13,2 $\mathrm{km}^{2}$, população de 143.992 habitantes em 2010 e densidade demográfica (habitante por $\mathrm{km}^{2}$ ) igual a 10,908.

Entre os anos 1940 e 1950, por meio de loteamentos de áreas mais afastadas do centro, iniciou-se o desenvolvimento urbano da Zona Leste que está relacionado com o padrão de crescimento periférico da cidade de São Paulo, caracterizado pela distância do centro e pela pobreza dos bairros. Nos anos 1970 e 1980, houve uma predominância deste padrão e, devido à demanda, neste período foram construídos os primeiros prédios da Companhia de Habitação de São Paulo, a Cohab, na Zona Leste, o que favoreceu o aumento na quantidade de moradores da região.

Nas delimitações da subprefeitura de São Mateus há 37 córregos e dois rios, o Aricanduva e o das Pedras. A região é também quase que completamente abarcada pela Bacia Hidrográfica do Rio Aricanduva (Fig. 02), uma das principais bacias hidrográficas da cidade de São Paulo, com cerca de $100,4 \mathrm{~km}^{2}$ de área de drenagem, cenário frequente de inundações nos períodos de chuva.

Devido ao crescimento da área urbana na Bacia Hidrográfica do Rio Aricanduva, surgiram, paulatinamente, os primeiros problemas com inundações, que se tornaram mais frequentes a partir dos anos 1960. Apenas dez anos depois, na década de 1970 , os casos de enchentes se intensificaram e passaram a ocorrer anualmente (Kobayashi 2010).

Por conta dos constantes problemas de inundações na referida Bacia, a Prefeitura do Município de São Paulo e o Metrô iniciaram as primeiras obras no local entre os anos de 1960 e 1970, e foi em 1963 que se iniciou a canalização do Rio Aricanduva. Nos anos 1990 foram implantados os reservatórios para contenção do excedente de águas pluviais, e a partir dos anos 2000 houve uma maior realização de obras, como novos piscinões, alteamentos, alargamentos de calhas, parques lineares e também há constantes limpezas e desassoreamentos (Kobayashi 2010).

Entretanto, apesar da realização de obras de engenharia com a finalidade de resolver ou ame- 
nizar a quantidade de casos de inundações, os problemas da região ainda são constantes. Em 2009, por exemplo, as águas do córrego Bento Henriques, pertencente ao distrito de São Mateus, subiram aproximadamente $1,2 \mathrm{~m}$ e atingiram 700 barracos (Folha de S. Paulo 2009).

Além dos moradores serem frequentemente afetados por inundações, parte da população local também é atingida por escorregamentos que ocorrem em alguns pontos do perímetro da subprefeitura de São Mateus, já que por conta da proximidade com a Serra do Mar, o relevo da região é acidentado (Fig. 3).

De acordo com a Defesa Civil Distrital, equipes de funcionários se revezam em 24 horas de trabalho por dia para monitorar pontos de alagamentos, áreas de encostas e margens de córregos com risco de escorregamentos nos períodos de chuva, entre novembro e abril. O órgão também atende cerca de 40 ocorrências por mês, sendo a maioria relacionada a casos de quedas de árvores, que têm maior incidência nesse período.

Segundo Kobayashi (2010), apesar de todas as obras de engenharia feitas na região para minimizar os episódios de inundações, poucas ações não estruturais foram realizadas no local destacando-se apenas algumas campanhas educativas abordando a problemática dos ratos e lixo, a operação Cata-Bagulho e atividades de educação ambiental promovidas pelo Parque do Carmo e pelo Serviço Social do Comércio, o SESC.

Em função dos frequentes episódios de inundações e dos seus problemas associados como lixo e ratos, e também devido às poucas ações não estruturais realizadas na região, é que se faz importante a implantação do projeto "Educar para prevenir: Proteção e Defesa Civil nas escolas por um currículo escolar vivo" nas escolas locais. O presente projeto apresenta uma perspectiva ampla que visa despertar, por meio da troca de conhecimentos técnicos e experiências, um olhar crítico e com bagagem informativa a respeito das problemáticas locais e as possíveis maneiras de minimizá-las.

A Defesa Civil do Município de São Paulo prioriza os planejamentos e execuções das ações emergenciais, no entanto, ações preventivas a longo prazo seriam mais eficazes, já que com trabalhos educativos seria possível reduzir o número de pessoas suscetíveis a acidentes decorrentes de desastres naturais, salvando vidas e diminuindo perdas materiais e recursos financeiros.

Além disso, a estrutura do planejamento de segurança do Município de São Paulo prevê a execução de medidas preventivas como, por exemplo, o desenvolvimento deste projeto que busca aprimorar a integração entre as comunidades de áreas de risco e a Defesa Civil, e inserir seu papel preventivo e educativo no cotidiano escolar.

\section{Fundamentação teórica}

Analisando o processo de urbanização brasileiro, observa-se que ocorreu de forma rápida na segunda metade do século XX. Em menos de cinquenta anos o Brasil deixou de ser um país com população predominantemente rural para se tornar um país com população majoritariamente urbana. Em função dessa intensa urbanização num curto intervalo de tempo, as cidades foram se adaptando para receberem esses novos moradores (Maricato 2008). O município de São Paulo, segundo dados dos censos demográficos do IBGE (1950 e 2000), foi uma dessas cidades que cresceram de forma intensa no final do século XX. A cidade aumentou quase cinco vezes a sua população, passou de aproximadamente 2,2 milhões de habitantes em 1950 para aproximadamente 10,4 milhões em 2000.

Segundo Maricato (2008), essa urbanização empurrou a população mais pobre para regiões menos centrais, muitas vezes invadidas, como regiões íngremes em morros ou áreas de várzea. Assim, o crescimento intenso e desordenado da cidade de São Paulo levou à ocupação de áreas inapropriadas, que se tornaram suscetíveis à ocorrência de acidentes.

$\mathrm{Na}$ cidade de São Paulo, os principais acidentes que afetam a população ocorrem, principalmente, nos períodos chuvosos e são decorrentes de construções em locais inapropriados e da impermeabilização do solo; são eles: escorregamento, enchente, inundação e alagamento. O escorregamento, segundo Tominaga (2011), é um tipo de movimento de massa de encosta, conhecido popularmente como deslizamento, que desloca, com velocidade de média a alta e sob a ação da gravidade, uma porção de solo e/ou rocha. Já as enchentes e inundações são processos naturais que, em função da ocupação de áreas de várzeas nas cidades, acabam prejudicando um número grande de indivíduos. Segundo Amaral et al. (2011), a enchente e a inundação ocorrem quando o nível de água do rio se eleva, sendo a enchente caracterizada pelo nível de água atingir a cota máxima do canal, mas não extravasar, e a inundação, pelo transbor- 
damento das águas além da cota máxima do canal. Já o alagamento é resultado de um sistema de drenagem urbano ruim, e se caracteriza pelo acúmulo momentâneo de águas num determinado lugar.

A partir destes breves histórico e conceituação, é possível refletir sobre os benefícios do trabalho integrado entre órgãos públicos e sociedade civil em ações realizadas nas escolas públicas como a conscientização entre os moradores da região sobre, por exemplo, o uso sustentável da água em seu bairro/ região. Esses benefícios incluiriam a participação dos órgãos públicos coletivamente, traduzindo a boa interação e diálogo entre gestões federais, estaduais e municipais; a observação de políticas municipais que, sobretudo gerenciam cada área inerente às subprefeituras locais; a divulgação nas escolas a respeito de ações preventivas e recuperativas como meio de introduzir a educação ambiental no ensino e, finalmente, o destaque da importância do uso consciente da água para crianças e adolescentes.

A articulação entre a Coordenadoria Municipal de Defesa Civil e as escolas públicas privilegia a população e diversos órgãos em suas respectivas atividades, e está prevista na Lei Federal n ${ }^{\circ} 12.608$, com publicação no DOU em 11/04/2012, que é um marco regulatório da Política Nacional de Proteção e Defesa Civil (PNPDEC), que insere no ambiente escolar suas diretrizes de prevenção, mitigação, preparação, resposta e recuperação voltadas à proteção e defesa civil. No que diz respeito à inserção de preceitos de proteção e Defesa Civil no ambiente escolar, o artigo 29 acrescenta no artigo 26 da Lei no 9.394 (Lei de Diretrizes e Bases da Educação Nacional), de 20 de dezembro de 1996, um novo parágrafo: " $₫ 7^{\circ}$ Os currículos do ensino fundamental e médio devem incluir os princípios da proteção e defesa civil e a educação ambiental de forma integrada aos conteúdos obrigatórios".

Ao considerar a escola como matriz de divulgações de atividades afirmativas em relação ao meio ambiente, pode-se considerar que é nesta mesma instituição que diversos profissionais podem se encontrar em motivação às dificuldades que são enfrentadas no dia-a-dia dos munícipes. Ao implantar os projetos propostos por esta parceria, as escolas terão o compromisso de fomentar o discurso de que a educação ambiental no século XXI é uma das poucas maneiras de prevenir os malefícios que a relação homem-natureza aponta nas últimas décadas.

Desta forma, investiga-se não só a maneira com que a educação ambiental pode ser inserida no contexto escolar, mas também como fazer com que as teorias sejam parte da prática cotidiana de todas as pessoas que irão participar de reuniões e encontros e, acima de tudo, frisar que a essência dos órgãos públicos não está apenas no atendimento das ocorrências emergenciais, mas sim na prevenção dos diversos eventos que os quadros naturais podem apresentar a qualquer momento, como é possível notar nos artigos abaixo do Decreto $\mathrm{n}^{\circ}$. $47.534 / 2006$, que insere no cotidiano escolar as atribuições competentes à Defesa Civil:

"Art. 60. Compete à Coordenadoria Municipal de Defesa Civil, de acordo com o artigo 13 do Decreto Federal no 5.376, de 17 de fevereiro de 2005: XII gerenciar os procedimentos relativos à mobilização comunitária e à implantação de NUDEC ou entidades correspondentes, especialmente nas escolas de nível fundamental e médio e em áreas de riscos intensificados e, ainda, implantar programas de treinamento de voluntários.(...) Art. 11. São atribuições do Coordenador de Ações Preventivas e Recuperativas:(...) IX - articular e viabilizar a inclusão dos princípios de defesa civil nos currículos escolares da rede municipal de ensino, proporcionando todo apoio à comunidade docente no desenvolvimento de material didático-pedagógico para esse fim, bem como a implementação de ações que possam envolver a comunidade.Art. 12. São atribuições da Coordenadoria de Apoio Operacional e Ações de Busca e Salvamento:(...) IV - organizar e promover campanhas educativas de utilidade pública e no âmbito escolar, para difusão e prática da cultura preventiva de acidentes domésticos e suporte básico da vida com o objetivo de evitar ou minimizar as perdas humanas e sócio-econômicas desses acidentes.”

Portanto, as ações citadas do Decreto $\mathrm{n}^{\circ}$. 47.534/2006 devem ser reconhecidas e inseridas no ambiente escolar, de modo a criar um espaço em que as crianças e adolescentes consigam visualizar a importância do conhecimento do local em que vivem e como agir diante de determinadas situações.

Ao se realizar experiências em sala de aula, é preciso conhecer o cotidiano dos alunos que têm uma realidade social mais carente, para que seja possível quebrar os limites e perceber o quanto o aluno pode auxiliar nas dinâmicas e como sua atuação é importante para o desenvolvimento de cada criança ou adolescente, agindo de acordo com a ideia de que é por meio da sensibilização e conscientização das crianças e adolescentes que se consegue estabelecer o início das relações sociais 
pautadas no respeito ao meio ambiente e à sociedade como um todo.

Sem esquecer que trabalhos com reciclagem não são e não devem ser a única forma de trabalhar conceitos em educação ambiental, a inserção, nesta área, de tarefas de reciclagem, é relevante para mostrar aos docentes a importância de tal abordagem em sala de aula, pois isto significa investigar as relações que a poluição urbana e industrial tem com o cotidiano de cada munícipe. Sabe-se também que as atividades industriais e a concentração populacional massificada estimulam a produção de resíduos sólidos, líquidos e gasosos de forma desordenada, os quais a natureza não tem potencial para absorver na escala de tempo de sua produção, e que são estes resíduos domésticos e industriais que habitualmente denominam o fenômeno da poluição ambiental. Esse excesso de rejeitos contribui gradativamente para a degradação ambiental, que consequentemente causa a perda da qualidade de vida.

Atualmente, o lixo doméstico (resíduos sólidos descartados pela dona de casa, restaurantes e bares) vem causando preocupação no âmbito do poder público, pois além dos agravantes que causam no meio ambiente, esta situação também aponta para o esgotamento dos recursos naturais e a importância da diminuição do uso de recursos e da reutilização de produtos, otimizando o aproveitamento das matérias-primas. Desta forma:

"O lixo gerado nas cidades tem-se tornado cada dia mais problemático por suas razões: a população urbana tornou-se muito numerosa e gera volumes de lixo cada vez maiores; a evolução técnica e o processo crescente de desenvolvimento industrial geram, cada vez mais, tipos de lixo que a natureza por si só não consegue destruir, como os plásticos e vidros, que não são biodegradáveis" (Ross 1996).

Neste trabalho, há a necessidade de incluir dois aspectos fundamentais: primeiro, como se concebe a educação ambiental na formação do cidadão nas escolas de ensino público e, segundo, a apropriação de alguns conceitos pertinentes à gestão em áreas de risco e como se dá a relação homem-meio na sociedade moderna.

Para o primeiro aspecto mencionado, ressalta-se a importância da Educação Ambiental no ambiente escolar, e é possível observar que nas últimas duas décadas o debate a respeito da conservação do meio ambiente ocorre com mais força. O termo "educação ambiental" foi utilizado pela primeira vez na Universidade de Keele, no Reino
Unido, em 1965, porém só em 1975, no I Seminário Internacional de Educação Ambiental, em Belgrado, ganhou um objetivo educativo específico por intermédio da UNESCO, que sugere a inserção da discussão acerca do ambiente na educação. A partir deste momento surgem diversos eventos visando aprimorar métodos que enquadrassem a educação ambiental no contexto escolar. Surge a primeira definição mais detalhada em 1977, no evento Taller Subregional de Educación Ambiental para Educación Secundaria - Chosica/Peru, 1976, frisando:

"La educación ambiental es la acción educativa permanente por la cual la comunidad educativa tiende a la toma de conciencia de su realidad global, del tipo de relaciones que los hombres establecen entre sí y con la naturaleza, de los problemas derivados de dichas relaciones y sus causas profundas. Ella desarrolla, mediante una práctica que vincula al educando con la comunidad, valores y actitudesque promoven un comportamiento dirigido hacia la transformación superadora de esa realidad, tanto en sus aspectos naturales como sociales, desarrollando en el educando las habilidades y aptitudes necesarias para dicha transformación.” (Unesco 1976 apud Azaziel et al. 2003)

Em relação ao Brasil, a educação ambiental aparece tardiamente, mas admite-se a existência de documentos na década de 1970 que já tratavam do assunto; mas definitivamente a partir de 1980 as temáticas ganham vigor e atingem as dimensões públicas. Oficialmente, na Constituição de 1988, Capítulo VI, sobre meio ambiente, no artigo 225, parágrafo primeiro, inciso IV, consta: "Promover a educação ambiental em todos os níveis de ensino e a conscientização pública para a preservação do meio ambiente", cabendo ao poder público assumir e administrar tal atividade. Em 1994, surge o Programa Nacional de Educação Ambiental/Pronea (BRASIL, 1994), em convênio entre o Ministério da Educação e o Ministério do Meio Ambiente, e interveniência do Ministério da Cultura e do Ministério da Ciência e Tecnologia, com a intenção de consolidar a educação ambiental como política pública.

Em 1996, com a elaboração dos Parâmetros Curriculares Nacionais, PCN (BRASIL, 1996), a temática referente ao meio ambiente apresenta-se como estudo articulado às propostas do currículo escolar e envolto a temas transversais das diversas áreas de conhecimento, de modo a propiciar uma prática educativa que incentive a visão global e 
abrangente da questão ambiental a partir de projetos pedagógicos definidos. No ano de 1999, publica-se a lei 9.795/99, que institui a Política Nacional de Educação Ambiental, frisando em seu artigo $2^{\circ}$ que: "A educação ambiental é um componente permanente da educação nacional, devendo estar presente, de forma articulada, em todos os níveis e modalidades do processo educativo, em caráter formal e não formal".

Foram analisados os PCN de Meio Ambiente, Geografia, Ciências, Biologia e Química, que propõem conteúdos para execução e desenvolvimento de atividades facilmente relacionáveis aos temas de Proteção e Defesa Civil, com o objetivo de fundamentar a execução do projeto. Diante disso, foram encontrados, das séries do ciclo I do Ensino Fundamental ( $1^{\circ}$ ao $5^{\circ}$ ano), 04 itens no PCN de Geografia, 08 no de Ciências e 14 no de Meio Ambiente, dando destaque ao seguinte conteúdo indicado no PCN de Meio Ambiente: "A participação em atividades relacionadas à melhoria das condições ambientais da escola e da comunidade local".

Quanto das séries do ciclo II do Ensino Fundamental $\left(6^{\circ}\right.$ ao $9^{\circ}$ ano), foram encontrados 34 itens no PCN de Geografia, 07 no de Ciências e 12 no de Meio Ambiente, dando destaque aos seguintes indicados no PCN de Ciências: "Ocupação de áreas de risco: alagadiços, encostas, etc." e "Políticas públicas urbanas (planos diretores, infraestrutura e a cidade apartada)". Em relação às séries do Ensino Médio, foram encontrados 16 itens no PCN de Biologia, 03 no de Química e 03 no de Geografia, dando destaque ao seguinte indicado no PCN de Biologia: "Avaliar as condições ambientais, identificando o destino do lixo e do esgoto, o tratamento dado à água, o modo de ocupação do solo, as condições dos rios e córregos e a qualidade do ar".

Também foram analisadas as Orientações Curriculares (OC), que são as diretrizes que regem as escolas municipais, das disciplinas de Geografia e Ciências. Neste documento, com relação às quatro séries do Ensino Fundamental ciclo II $\left(6^{\circ}\right.$ ano $/ 5^{\mathrm{a}}$ série até o $9^{\circ}$ ano $/ 8^{\mathrm{a}}$ série), foram encontrados 28 itens nas OC de Ciências, dando destaque para o seguinte: "Identificar as bacias hidrográficas e sua função na economia e em relação aos impactos ambientais, a partir de interpretações cartográficas do espaço geográfico brasileiro", e 23 itens nas OC de Geografia, destacando o seguinte: "Valorizar atitudes individuais e coletivas que contribuam para a preservação do meio ambiente no país, na cidade e em sua comunidade".
Deve-se entender que a educação como prática social com o objetivo de aprimoramento dos diversos saberes existentes em uma cultura, e de acordo com as necessidades de uma dada sociedade, deve ser compreendida como modo de atuação sobre a vida humana em duas perspectivas: "no desenvolvimento da produção social como cultura, mesmo dos meios instrumentais e tecnológicos de atuação no ambiente; e na construção e reprodução dos valores sociais". (Brandão 1986 apud Azaziel et al. 2003). Assim, assegurar que a criança e o adolescente aprendam os valores para a conservação do meio ambiente, a fim de evitar eventos que acabem por destruir ou prejudicar a região em que vivem, não reflete apenas a inserção de mais uma atividade na escola, mas implica na formação do cidadão consciente de que a preservação da natureza é significante à própria interação positiva da sociedade como um todo.

Para o segundo aspecto mencionado, a respeito da apropriação de alguns conceitos pertinentes ao gerenciamento em áreas de risco, é indispensável considerar a gestão dos recursos naturais como forma de articular a contenção de problemas em áreas de risco contribuindo para o debate da questão ambiental; portanto, é preciso considerar os estudos no meio ambiente atrelados à prevenção de riscos como uma discussão interdisciplinar, mas não apenas no âmbito acadêmico ou escolar, e sim em uma perspectiva de ações na própria sociedade que transcendem à investigação da educação ambiental por si própria. Desta forma:

\footnotetext{
"A questão ambiental é, assim, mais que um campo interdisciplinar, pois nela se intercruzam o conhecimento técnico-científico; as normas e valores; o estético-cultural, regidos por razões diferenciadas, porém não-dicotômicas. Ela requer um campo de comunicação intersubjetiva não viciado e não manipulado para que a região comunicativa possa se dar efetivamente. Enfim, requer, fundamentalmente democracia.” (Gonçalves 1990 apud Maia 2005).
}

Estabelece-se assim a prioridade em criar documentos e articular planos que efetivamente gerem ações que serão realizadas de forma coletiva, pois o que se observa até o momento são empreendimentos que apresentam gerenciamento ineficiente quanto à consideração em relação ao local em se está inserido. Há também a questão das queimadas, que mais uma vez atendem demandas voltadas ao mercado, subestimando a existência da natureza, dentre outras atividades. As pesquisas relaciona- 
das às estruturas que privilegiam a preservação do ambiente tornam-se interessantes à medida que os recursos naturais atualmente são cada vez mais escassos diante das atividades antrópicas. Assim, a necessidade de estudos que enfatizem a conservação é de importância desde que consiga atingir órgãos públicos federais, estaduais e municipais, entidades privadas e a própria sociedade civil.

\section{Metodologia}

Visando a conhecer cada escola para que haja uma eficiente disseminação de conceitos básicos de Proteção e Defesa Civil, a primeira etapa de desenvolvimento do projeto consistiu na aplicação de um questionário em parceria com a Diretoria Regional de Ensino de São Mateus. O objetivo do questionário foi avaliar a percepção do corpo diretivo da escola a respeito dos eventuais riscos ambientais existentes no entorno, conhecer as condições de infraestrutura da escola e, principalmente, buscar informações a respeito de possíveis projetos ou atividades em andamento na instituição de ensino relacionadas ao tema.

É necessário reconhecer que a pesquisa de campo tornou-se fundamental ao trabalho realizado pela Coordenadoria Municipal de Defesa Civil em parceria com as diretorias de ensino, pois, ao trabalhar com a realidade da comunidade situada em áreas de risco, a primeira necessidade que deve ser apontada é a percepção que os munícipes têm da região em que habitam. A essência da pesquisa realizada por meio dos questionários aplicados, portanto, pode ser traduzida como:

"Atividade cotidiana considerando-a como atitude, um 'questionamento sistemático', crítico e criativo, mais uma intervenção competente na realidade, ou o diálogo crítico permanente com a realidade em sentido teórico e prático" (Demo 1996 apud Moresi 2003).

Assim, pensar na utilidade da pesquisa ao trabalho desenvolvido requer considerar a percepção que cada indivíduo tem da situação à qual está submetido, ou seja, aquele que mora em lugares em que há forte incidência de enchentes, escorregamentos, inundações, entre outros eventos, evidentemente terá mais condições para distinguir e buscar auxílio em relação aos procedimentos preventivos e emergenciais em tais ocorrências. Porém, os cidadãos considerados com menos instrução ou que têm menor acesso aos meios de comunicação raramente saberão onde procurar orientações em casos de ocorrência de eventos específicos.

$\mathrm{Na}$ pesquisa qualitativa, a percepção, portanto, será a matriz dos estudos que identificam o quanto os indivíduos conseguem visualizar da realidade que os cercam. Desta maneira:

"A pesquisa qualitativa tem o ambiente natural como sua fonte direta de dados e o pesquisador como seu principal instrumento. (...) 2. Os dados coletados são predominantemente descritivos. (...) 3. A preocupação com o processo é muito maior do que com o produto. (...) 4. O 'significado' que as pessoas dão às coisas e à sua vida são focos de atenção especial pelo pesquisador. (...) 5 . A análise dos dados tende a seguir um processo indutivo. Os pesquisadores não se preocupam em buscar evidências que comprovem hipóteses definidas antes do início dos estudos. As abstrações se formam ou se consolidam basicamente a partir da inspeção dos dados num processo de baixo para cima." (Ludke e André 1986 apud Garnica 1996)

Ao utilizar este método de pesquisa em que os munícipes expõem sua interpretação e conhecimento do que é uma área de risco e seus agravantes, é preciso considerar a percepção que o público-alvo tem da situação estudada, isto significa, observar a que perfil o questionário foi aplicado, se as condições a que estas pessoas estão submetidas as torna capazes de discernir o que está sendo indagado e, sobretudo, ao destacar que reconhecem os problemas existentes em seu respectivo bairro, se as mesmas têm participado de ações que minimizem tais eventos.

Após a devolução dos questionários preenchidos, iniciou-se o processo de tabulação dos dados e separação das escolas de acordo com a realização ou não de projetos e por faixa etária atendida. Com essa etapa finalizada, foi possível localizar com mais rapidez as escolas inseridas em áreas de risco com maior potencial para ocorrência de acidentes. Este procedimento facilitou a proposta de implementação do projeto nas escolas que não desenvolvem nenhuma atividade ou de complementação e parceria com aquelas que já possuem projetos, no entanto, por motivos de gestão, a comunicação com a Diretoria de Ensino de São Mateus foi interrompida.

Porém, em uma retomada futura do projeto, será estudada a melhor maneira para introdução dos conceitos de Proteção e Defesa Civil no ambiente escolar, e com a participação dos professores, o pro- 
jeto poderá ser aprimorado para se adequar com a realidade de cada escola e moldado para os diferentes níveis de ensino visando adaptar-se às diversas idades e atividades lecionadas na unidade escolar.

A partir da troca de conhecimentos e experiências, os docentes receberão orientações para correlacionar os assuntos pré-definidos pelos Parâmetros Curriculares Nacionais e pelas Orientações Curriculares, propostas estas que visam a padronização do ensino estadual e municipal, respectivamente, em todo o território nacional, com os temas relacionados aos riscos ambientais, como inundações, deslizamentos, incêndios, acidentes domésticos, etc.

Também será proposta a criação de módulos seqüenciais para serem desenvolvidos pelos professores eventuais e pelos professores de complementação de jornada (substitutos) das redes estadual e municipal, respectivamente. Essa proposta objetiva um maior aproveitamento das aulas nas escolas em que há professores faltosos, pois além de inserir a discussão de Proteção e Defesa Civil, irá fundamentar o conhecimento já trabalhado pelos demais professores, permitindo também que alunos interessados possam se inserir em projetos sobre o tema.

Para a aplicação do projeto, foram elaboradas propostas de atividades e maneiras de execução de acordo com as faixas etárias, visando sempre realizar atividades adequadas para cada etapa do ensino.

Para alunos entre 0 e 5 anos: na faixa entre 0 e 3 anos os alunos são atendidos pelos Centros de Educação Infantil (CEI), e entre 3 e 5 anos são atendidos pelas Escolas Municipais de Educação Infantil (EMEI). Devido a pouca idade das crianças atendidas por essas instituições, as atividades propostas nestas etapas da educação terão como foco a realização de projetos que envolvam os alunos e, principalmente os pais, buscando uma maior concretização do conhecimento transmitido e possibilitando o engajamento dos pais nos processos de mobilização das comunidades por meio dos Núcleos de Defesa Civil.

Para alunos entre 6 e 10 anos: nessa faixa etária os alunos estão entre o $1^{\circ}$ e o $5^{\circ}$ ano do ciclo I do ensino fundamental, e podem ser atendidos tanto pelas Escolas Estaduais (EE) quanto pelas Escolas Municipais de Ensino Fundamental (EMEF). Nesta etapa será inserida a percepção do ambiente e a sua importância para a prevenção de acidentes por meio de atividades lúdicas e explicativas que serão desenvolvidas ao longo dos 5 anos de dura- ção desse ciclo.

Para alunos entre 11 e 12 anos: nesta etapa os alunos estão entre o $6^{\circ}$ e $7^{\circ}$ ano do ciclo II do ensino fundamental, e são atendidos pelas EE e EMEF. Nessa fase serão realizadas atividades que expliquem mais profundamente os conceitos e processos já estudados no ciclo anterior; a idade mais avançada deste grupo de alunos possibilitará tornar mais complexos os temas ambientais utilizando documentos como, por exemplo, a Agenda 21, para que os alunos adquiram noções gerais de Proteção e Defesa Civil e percepção de riscos ambientais.

Para alunos entre 13 e 14 anos: nesta fase os alunos estão cursando entre o $8^{\circ}$ e $9^{\circ}$ ano do ciclo II do ensino fundamental, e são atendidos pelas EE e EMEF. Desenvolverão, nesta etapa, atividades que propõem a criação, desenvolvimento e execução na escola de projetos permanentes e o estabelecimento de formas de discussão.

Para alunos entre 15 e 17 anos: com essa faixa etária, os alunos estão cursando entre o $1^{\circ}$ e $3^{\circ}$ ano do ensino médio, e somente são atendidos pelas EE. Nesta etapa será proposta a continuidade de desenvolvimento e execução de projetos, no entanto, visando a aplicabilidade também na comunidade.

Neste sentido, é necessário considerar o padrão de desenvolvimento das crianças e adolescentes, a fim de estabelecer atividades que contemplem todos de maneira satisfatória e, além disso, ao se levar em conta a faixa etária das pessoas que compõem a comunidade escolar, pode-se realizar a incorporação de ações que sejam aplicáveis aos munícipes das regiões que estão no entorno da escola. Essa dinâmica que torna possível visualizar a percepção dos moradores residentes no entorno de áreas de risco é facilitada por meio da formulação de questionários, como o elaborado para a concepção deste projeto, mostrando que as ações conjuntas entre órgãos públicos e munícipes rendem bons resultados.

\section{Resultados pretendidos}

Espera-se que os docentes apliquem em aula os conhecimentos técnicos adquiridos de forma prática e didática, para que o interesse e curiosidade estimulem os alunos a tornarem-se multiplicadores em suas residências e bairros. A longo prazo é esperado que tal dispersão de informações incentive a população a constituir Núcleos de Defesa Civil e participar ativamente para que não fiquem totalmente dependentes dos 
órgãos públicos em situações de suscetibilidade de riscos ambientais.

Respeitando as escalas do espaço geográfico este projeto piloto será, primeiramente, aplicado em escolas municipais, especificamente as unidades da Subprefeitura de São Mateus, e estima-se que os resultados positivos do seu desenvolvimento viabilizem sua adequação e aplicação também nas escolas estaduais da cidade de São Paulo. Porém, a pesquisa só será ampliada após os resultados iniciais que servirão como diagnóstico ao planejamento de ações para o Estado de São Paulo.

\section{Conclusão}

Ao decorrer da elaboração do projeto "Educar para prevenir: Proteção e Defesa Civil nas escolas por um currículo escolar vivo", a realização das pesquisas dos PCN e das OC, as observações das condições apresentadas nos questionários, juntamente com as ações já praticadas pelo corpo de funcionários da COMDEC, propiciaram concluir que não há necessidade de criação de um novo currículo ou nova disciplina para tratar dos temas de riscos geológicos e ambientais, visto que já estão atrelados aos saberes interdisciplinares de diretrizes escolares.

Ao se tratar de desastres naturais, e principalmente da relação homem-meio, pressupõe-se a presença desses temas nas disciplinas como a Geografia (que tratará dos aspectos físicos de uma dada região); Sociologia (que trata da sociedade em sua perspectiva mais ampla); ou mesmo, a Filosofia (quando se considera a percepção dos munícipes ou de um determinado grupo que more em lugares que são acometidos por eventos causados pela natureza ou pela ação humana atrelada ao meio ambiente). Portanto, registra-se na elaboração desse projeto não apenas a inter-relação de diversos temas de cunho acadêmico (citados anteriormente), mas também o debate sobre estes assuntos na unidade escolar que é a fonte de conscientização e responsável por propiciar a democracia e o respeito que devem prevalecer nas relações humanas.

Sabendo-se que tanto os PCN quanto as OC propõem conteúdos para desenvolvimento em aula que são facilmente relacionáveis com a temática de riscos geológicos e ambientais, e que as próprias disciplinas, em sua essência, já abordam tais conteúdos, entendemos que é indispensável difundir conhecimentos técnicos aos docentes para permitir que tais assuntos pré-definidos sejam trabalhados da maneira mais completa possível, não apenas para obedecer as legislações ou as diretrizes escolares, mas, principalmente, para formar cidadãos com maior percepção e cuidado com o bairro onde residem e, portanto, com o meio que ocupam.

Concluímos também que a aplicação dos questionários para diagnóstico de cada unidade foi uma ferramenta que aprimorou o projeto, já que proporcionou um entendimento a respeito da percepção que as pessoas possuem da região onde residem, e favorecerá a inserção do presente projeto nas escolas, seja para auxiliar e acrescentar em um projeto já existente ou para dar início a uma nova atividade escolar.

\section{Referências bibliográficas}

Amaral R., Gutjahr M. R. 2011. Desastres naturais. São Paulo: IG/SMA.

Azaziel M., Franca N., Loureiro C.F.B. 2003. Educação Ambiental e Gestão Participativa em Unidades de Conservação. Rio de Janeiro: IBASE.

Brasil. Lei $n^{\circ}$ 12.608, de 11 de abril de 2012. Brasília, DF, Senado, 2012.

Folha de S. Paulo. 2009. Temporal causa inundações e protesto em SP. Folha de São Paulo, 02 Fev. 2009, Cad. C, Cotidiano. URL: http://www1. folha.uol.com.br/fsp/cotidian/ff2402200922. htm. Acesso 25.07.2012.

Garnica A.V.M. 1996. Algumas notas sobre Pesquisa Qualitativa e Fenomenologia. Apresentado no evento Paradgimas de interpretação da realizada. Botucatu: UNESP.

Instituto Brasileiro de Geografia e Estatística, IBGE. URL: http://www.ibge.gov.br/home/estatistica/ populacao/condicaodevida/indicadoresminimos/notasindicadores.shtm. Acesso 15.04.2013.

Kobayashi M.Y. 2010. As enchentes do rio Aricanduva e a construção de conhecimento no ensino de geografia. São Paulo: Fac. Filos., Letr. Ciênc. Hum., USP. 115p. (Dissert. Mestr., Progr. Pós-Grad. Geogr. Hum.).

Maia M.S.S. 2005. Educação Ambiental em Intervenções de Saneamento: A experiência do Programa Bahia Azul na Comunidade da Bacia de Alto Pituaçu, Salvador: UFBA. (Dissert. Mestr, Depto. Biologia.

Maricato E. 2008. Brasil, cidades: alternativas para a crise urbana. Petrópolis: Vozes.

Moresi, E. [org]. 2003. Metodologia de Pesquisa. Brasília: Universidade Católica de Brasília.

Prefeitura da Cidade de São Paulo. Secretaria Mu- 
nicipal de Coordenação das Subprefeituras. s.d. Dados demográficos. URL: http://www.prefeitura.sp.gov.br/cidade/secretarias/subprefeituras/ subprefeituras/dados_demograficos/. Acesso 11.07.2013.

Prefeitura da Cidade de São Paulo. Secretaria Municipal de Desenvolvimento Urbano. s.d. URL: http://smdu.prefeitura.sp.gov.br/historico_demografico/img/mapas/1992.jpg. Acesso 11.07.2013.

Prefeitura da Cidade de São Paulo. Subprefeitura São Mateus. s.d. URL: http://www.prefeitura. sp.gov.br/cidade/secretarias/subprefeituras/sao mateus/noticias/?p=36459. Acesso 11.07.2013. Ross J.L.S. [org]. 2000. Geografia do Brasil. São Paulo: Edusp.

São Paulo (Município). 2006. Reorganização do Sistema Municipal de Defesa Civil. Decreto n ${ }^{\circ}$ 47.534, de 1 de agosto de 2006. Adequa a organização do Sistema Municipal de Defesa Civil. São Paulo, SP.

Tominaga L.K., Santoro J., Amaral R.do [orgs.]. 2011. Desastres naturais: conhecer para prevenir. São Paulo: Inst. Geol. 